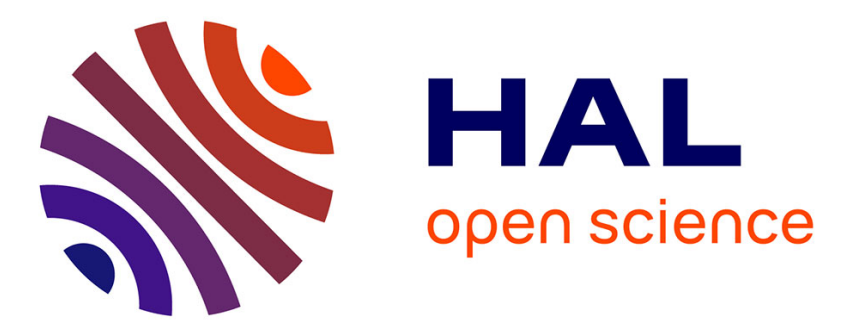

\title{
Inverse prediction of local interface temperature during electromagnetic pulse welding via precipitate kinetics
}

J.S. Li, T. Sapanathan, R.N. Raoelison, Z. Zhang, X.G. Chen, D. Marceau, A. Simar, M. Rachik

\section{- To cite this version:}

J.S. Li, T. Sapanathan, R.N. Raoelison, Z. Zhang, X.G. Chen, et al.. Inverse prediction of local interface temperature during electromagnetic pulse welding via precipitate kinetics. Materials Letters, 2019, 249, pp.177 - 179. 10.1016/j.matlet.2019.04.094 . hal-03484376

\section{HAL Id: hal-03484376 \\ https://hal.science/hal-03484376}

Submitted on 20 Dec 2021

HAL is a multi-disciplinary open access archive for the deposit and dissemination of scientific research documents, whether they are published or not. The documents may come from teaching and research institutions in France or abroad, or from public or private research centers.
L'archive ouverte pluridisciplinaire HAL, est destinée au dépôt et à la diffusion de documents scientifiques de niveau recherche, publiés ou non, émanant des établissements d'enseignement et de recherche français ou étrangers, des laboratoires publics ou privés.

\section{(ㄷ)(1) $\$$}

Distributed under a Creative Commons Attribution - NonCommercial| 4.0 International 


\title{
Inverse prediction of local interface temperature during electromagnetic pulse welding via precipitate kinetics
}

\author{
J.S. Li ${ }^{1}$, T. Sapanathan ${ }^{1,2, *}$, R.N. Raoelison ${ }^{1,3}$, Z. Zhang ${ }^{4}$, X.G. Chen ${ }^{4}$, D. Marceau ${ }^{4}$, \\ A. $\operatorname{Simar}^{2}$, M. Rachik ${ }^{1}$ \\ ${ }^{1}$ Sorbonne universités, Université de technologie de Compiègne, laboratoire Roberval, FRE 2012 CNRS, \\ Centre de recherche Royallieu, CS 60319, 60203 Compiègne cedex, France \\ ${ }^{2}$ UCLouvain, Institute of Mechanics, Materials and Civil Engineering, 1348 Louvain-la-Neuve, Belgium \\ ${ }^{3}$ Université de Bourgogne Franche-Comté - UTBM, Laboratoire Interdisciplinaire Carnot de Bourgogne, \\ UMR 6303 CNRS, 90100 Belfort, France \\ ${ }^{4}$ Aluminium Research Centre-REGAL, University of Quebec at Chicoutimi, Chicoutimi, QC, G7H 2B1, \\ Canada \\ *Corresponding author: Thaneshan Sapanathan (email: thaneshan.sapanathan@uclouvain.be)
}

\begin{abstract}
:
Interface temperature of electromagnetic pulse welding is difficult to measure by insitu methods. Here, the local temperature rise is investigated using the kinetics of precipitates and dispersoids (transformation or dissolution) at the interface zone (IZ) and affected zone (AZ) of three welds. This fine scale analysis allows estimating of local temperature range for AZ that reaches between $250-360^{\circ} \mathrm{C}$ on both sides of narrow IZ, while the IZ itself experiences between $360-500{ }^{\circ} \mathrm{C}$ or even beyond $500{ }^{\circ} \mathrm{C}$. The interface temperature increases with the increasing impact intensity. The current work estimated thermal field based on the precipitate transformations, which played an important role in the ultra-fast temperature rise of the interface during electromagnetic pulse welding.
\end{abstract}

Keywords: Interfaces, Thermal analysis, Precipitates, Phase transformation, Welding

\section{Introduction}

Electromagnetic pulse welding (EMPW) becomes a growing interest in automotive industry, thanks to its capability to weld similar and dissimilar materials and to produce lightweight structures for reducing greenhouse gas emission [1, 2]. The impact completes 
within hundreds $\mu$ s along with high-speed (hundreds of $\mathrm{m} / \mathrm{s}$ ) collision and an extremely high strain rate of up to $10^{6}-10^{7} \mathrm{~s}^{-1}$ at the interface [3]. EMPW has also been known as a solid-state cold welding since it does not use a heat source to weld materials as for conventional welding [4]. However, excessive local shear deformation during high-speed collision can heat the interface while producing a welded joint with a thermally activated diffusion [5].

The local interface temperature of the joint is usually predicted using analytical calculation [6] or computational modelling [7] during this high-speed dynamic process. However, investigating the evolution of precipitates across the interface enables to better understand the local temperature rise at a fine scale and to classify the zones, which have experienced different thermomechanical conditions during EMPW. Therefore, this study focuses on the transformation and dissolution of precipitate and dispersoids kinetics across the interface to establish the understanding of the thermal field across the interface of EMPW joints.

\section{Material and methods}

Evaluation of precipitates and their kinetics are investigated for EMPW aluminum samples using TEM observations. AA6061-T6 was used as the base material (BM). The microstructure of the base material is provided in supplementary material. The welding tests are performed using EMPW $25 \mathrm{~kJ}$ - 9kV machine equipped with a $690 \mu \mathrm{F}$ capacitor bank and a coil system composed of a three turn coil and a field shaper that generates $10 \mathrm{kHz}$ pulse electric current. The welding parameters [discharge voltage, initial air gap] are set to obtain three different welding conditions with: (1) low impact intensity $[6.5 \mathrm{kV}, 3 \mathrm{~mm}]$, (2) medium 
impact intensity $[7.5 \mathrm{kV}, 4 \mathrm{~mm}]$ and (3) high impact intensity $[8.5 \mathrm{kV}, 4 \mathrm{~mm}]$. These samples are referred to as Sample 1, Sample 2, and Sample 3, respectively.

\section{Results and discussion}

The evolution of precipitates due to the high-speed collision is shown in Fig. 1 in the interface zone (IZ) and thermally and mechanically affected zone (AZ). The heat source that activates this precipitates transformation in these zones is produced by the plastic work due to the extensive shear deformation during the interfacial collision. In what follows, the identification of temperature ranges for different precipitates are based on a literature survey [8-10]: $\beta^{\prime \prime}$ : dissolution $250^{\circ} \mathrm{C}, \beta^{\prime}$ : formation $250^{\circ} \mathrm{C}$ and dissolution $360^{\circ} \mathrm{C}, \beta$ : formation $360^{\circ} \mathrm{C}$ and dissolution $500^{\circ} \mathrm{C}$. The $\beta^{\prime}$ precipitates are distinguished from the $\beta$ precipitates due to their difference in shape, rod-shaped and square shaped [11], respectively.

Figs. 1a and b are obtained from Sample 1 corresponding to the lowest impact intensity. In the AZ (Fig 1b), the $\beta^{\prime}$ precipitates area fraction is about $0.19 \%$ (see statistical analysis below for more detail) which is the lowest among those three welding cases. The presence of low amount of $\beta^{\prime}$ precipitates and the complete absence of $\beta^{\prime \prime}$ in the AZ suggest the temperature has overpassed the $\beta^{\prime \prime}$ dissolution temperature, i.e. larger than $250^{\circ} \mathrm{C}$, in that zone [8]. No square-shaped larger $\beta-\mathrm{Mg}_{2} \mathrm{Si}$ precipitates are evidenced in that zone. The IZ contains $\beta^{\prime}$ and $\beta$ precipitates (Fig. 1a). The presence of a square-shaped $\beta-\mathrm{Mg}_{2} \mathrm{Si}$ precipitate is clearly evidenced in Fig. 1a and this is found throughout the IZ. A high dislocation density is observed in the zone of $\beta^{\prime}$ and $\beta$ precipitates formation (Fig. 1a) which is a sign of the extensive plastic deformation in IZ. Together, these observations (Fig. 1a-b) indicate that the IZ experiences the transformation of $\beta^{\prime \prime} \rightarrow \beta^{\prime} \rightarrow \beta$, which allows to estimate the reached 
temperature to be between $360{ }^{\circ} \mathrm{C}-500{ }^{\circ} \mathrm{C}$ for IZ and between $250{ }^{\circ} \mathrm{C}-360{ }^{\circ} \mathrm{C}$ for $\mathrm{AZ}$.

The microstructural changes for the medium impact intensity (Sample 2) are presented in Figs. 1c and d. Whereas, Sample 1 exhibits more equiaxed grain (Fig. 1b, highlighted by yellow dashed line), Sample 2 has elongated fine grain (Fig. 1d, highlighted by yellow dashed line) that indicates plastic work is more intense in Sample 2. The grains are flattened due to the high strain rate shearing. Macroscopic elongations within a highly confined shearing have also been clearly evidenced in previous studies [12]. The elongated fine grains are dominant for Sample 2 (Fig. 1d) and coexist with a few equiaxed grains showing thereby the onset of more significant recrystallization. Furthermore, the IZ of Sample 2 has a higher density of $\beta^{\prime}+\beta$ precipitates (Fig. 1c) that suggests the temperature is slightly higher than that of Sample 1.

For the high impact intensity case (Sample 3), TEM observations of the IZ show only small amount of $\beta^{\prime}$ and $\beta$ precipitates and even more elongated and flattened grains (Fig. 1e). This result indicates significant increase of dissolution of precipitates in the IZ zone due to the increase of heating resulting from large plastic deformation.

Moreover, a qualitative TEM image analyze using a series of images obtained from those three welding conditions are used to compare the area fraction of dispersoids, $\beta^{\prime}$ and $\beta$ precipitates, and the findings are summarized in Fig. 2. We made the statistical analysis based on the 2D images, which are indeed come from the projected area of 3D thin volume of TEM samples. Here, we reasonably assumed all the TEM samples are in similar thickness and sufficiently thin. Since they represent the projected area, it has been called as "area fraction" in this manuscript. 


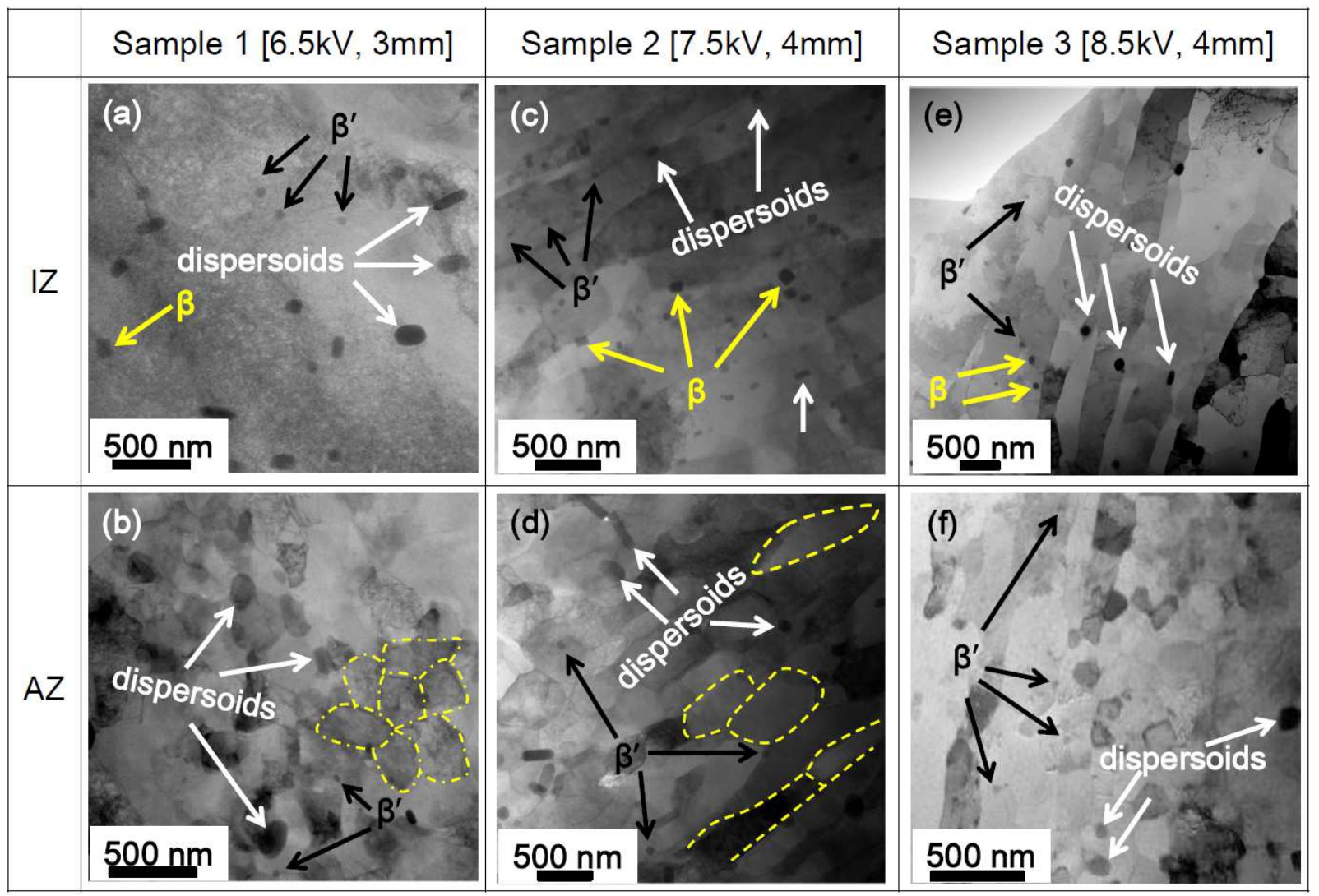

Fig. 1. TEM images of the AA6061-T6/AA6061-T6 interface obtained at various impact intensities; Sample 1: (a) Bright field (BF) image showing high density dislocations, $\beta^{\prime}+\beta$, dispersoids in IZ (b) dispersoids and $\beta^{\prime}$ in AZ, some equiaxed grains; Sample 2: (c) high density of $\beta^{\prime}+\beta$ in IZ (d) few equiaxed grains and elongated fine grains, and dispersoids with various shapes in AZ; Sample 3: (e) IZ showing low content of $\beta^{\prime}+\beta$ and dispersoids (f) Few $\beta^{\prime}$ and dispersoids in AZ.

The dispersoid fraction decreases slightly in the AZ from Sample 1 to Sample 3, and more significantly in the IZ due to the increase of impact intensity (increase of local temperature and pressure from Sample 1 to Sample 3). The typical $50 \mu$ s of the welding time with the temperatures below $500{ }^{\circ} \mathrm{C}$ [13] are not expected to lead to this dissolution, however the large plastic deformation in the IZ may occur due to this interesting phenomenon.

As discussed earlier, the transformation of $\beta^{\prime \prime} \rightarrow \beta^{\prime}$ is observed in the AZ with the absence of $\beta$ in all three cases while the area fraction of $\beta^{\prime}$ in AZ increased from Sample 1 to Sample 3, respectively, due to increased local heating. This result indicates that the temperature in $\mathrm{AZ}$ in Sample 3 reaches the highest values while it still remains below the $\beta^{\prime} \rightarrow \beta$ transformation 
temperature $\left(360{ }^{\circ} \mathrm{C}\right)[8]$. It corroborates with the observations (Fig. 1), where no $\beta-\mathrm{Mg}_{2} \mathrm{Si}$ precipitates are found in the AZ in any of these samples. The area fraction of $\beta^{\prime}+\beta$ in IZ is also overlaid in Fig. 2. It shows an increase of $\beta^{\prime}+\beta$ in IZ when increasing the impact intensity from Sample 1 to Sample 2. However, for Sample 3 contains a very low fraction of $\beta^{\prime}+\beta$ that can be attributed to the temperature in IZ exceeding the $\beta$ dissolution peak, i.e. a temperature around $500{ }^{\circ} \mathrm{C}[10]$. Supplementary material summarizes these findings.

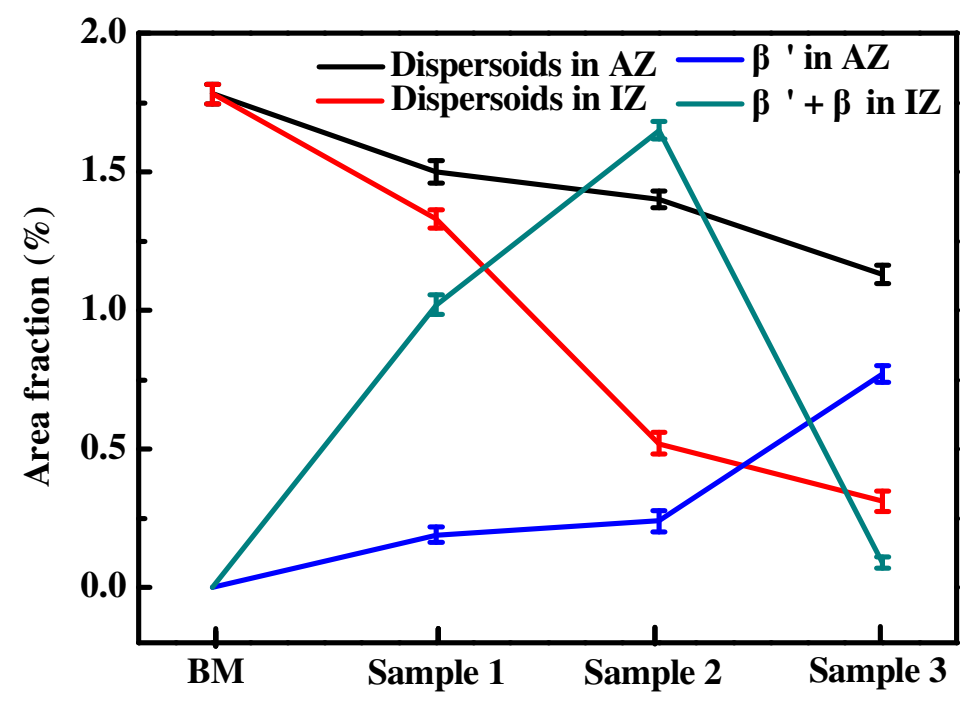

Fig. 2. Area fraction of dispersoids in both $A Z$ and IZ, $\beta^{\prime}$ in the $A Z$ and $\beta^{\prime}+\beta$ in the $I Z$ corresponding to the EMPW samples. Base material (BM) data is added here for comparison purpose, it should be considered irrespective of $\mathrm{AZ}$ and IZ. The standard deviation (SD) obtained from the statistical analysis of a series of images come from different zones are added here as the error bar.

\section{Conclusions}

In summary, the present study shows an inverse prediction of the thermal confinement during EMPW using TEM nanoscale analysis. The TEM results in the AZ zone shows the dissolution $\beta^{\prime \prime}$ precipitates of base material and transformation to $\beta^{\prime}$ precipitates, providing the temperature is reached between $250{ }^{\circ} \mathrm{C}$ and $360{ }^{\circ} \mathrm{C}$ in that zone. The formation of $\beta$ precipitates from successive $\beta^{\prime \prime} \rightarrow \beta^{\prime} \rightarrow \beta$ transformation indicates a temperature of $360^{\circ} \mathrm{C}$ to $500^{\circ} \mathrm{C}$ has been reached during the interfacial collision. These $\beta$ precipitates are dissolved 
within the IZ zone at the high intense impact condition $[8.5 \mathrm{kV}, 4 \mathrm{~mm}]$ and reveals thereby the temperature in that weld has reached beyond $500{ }^{\circ} \mathrm{C}$. Thus, the precipitate analysis permitted an inverse estimation of the temperature range at the fine scale resolution of TEM during the ultra-fast welding process.

\section{Conflict of interest}

None.

\section{Acknowledgements}

Authors acknowledge "Région Picardie" and "Le fonds européen de développement économique et régional (FEDER)" for funding of the MSIM (2010/2012) and COILTIM (2014/2020) projects. JSL acknowledges financial support of China Scholarship Council (CSC) for his PhD scholarship. TS acknowledges FRS-FNRS (Belgium) during postdoc at UCLouvain. AS acknowledges European Research Council (ERC grant n_716678).

\section{Supplementary material}

Supplementary data associated with this article is available in the online version.

\section{References}

[1] H.H. Geng, J.Q. Mao, X. Zhang, G.Y. Li, J.J. Cui. Mater. Lett. 245 (2019) 151-154.

[2] A. Kapil, A. Sharma, J. Clean. Prod. 100 (2015) 35-58.

[3] Y. Zhang, S.S. Babu, G.S. Daehn, J. Mater. Sci. 45 (2010) 4645-4651.

[4] J. Cui, C. Sun, J. Xu, Z. Xu, X. Huang, G. Li, J. Mater. Process. Technol. 227 (2016) 138-146.

[5] T. Sapanathan, R.N. Raoelison, N. Buiron, M. Rachik, Scr. Mater. 128 (2017) 10-13.

[6] A. Ben-Artzy, A. Stern, N. Frage, V. Shribman, Sci. Technol. Weld. Join. 13 (2008) 402-408.

[7] R.N. Raoelison, J. Li, T. Sapanathan, E. Padayodi, N. Buiron, D. Racine, Z. Zhang, D. Marceau, M. Rachik, Materialia. 5 (2019) 100205.

[8] J.A. Vargas, J.E. Torres, J.A. Pacheco, R.J. Hernandez, Mater. Des. 52 (2013) 556-564.

[9] V. Malin, Weld Res Supl 74 (1995) 305-318.

[10] A. Simar, Y. Bréchet, B. de Meester, A. Denquin, T. Pardoen, Mater. Sci. Eng. A. 486 (2008) $85-95$.

[11] S.J. Andersen, H.W. Zandbergen, J. Jansen, C. Træholt, U. Tundal, O. Reiso, Acta Mater. 46 (1998) 3283-3298.

[12] R.N. Raoelison, T. Sapanathan, E. Padayodi, N. Buiron, M. Rachik, J. Mech. Phys. Solids 96 (2016) 147-161.

[13] F. Qian, S. Jin, G. Sha, Y. Li, Acta Mater. 157 (2018) 114-125. 


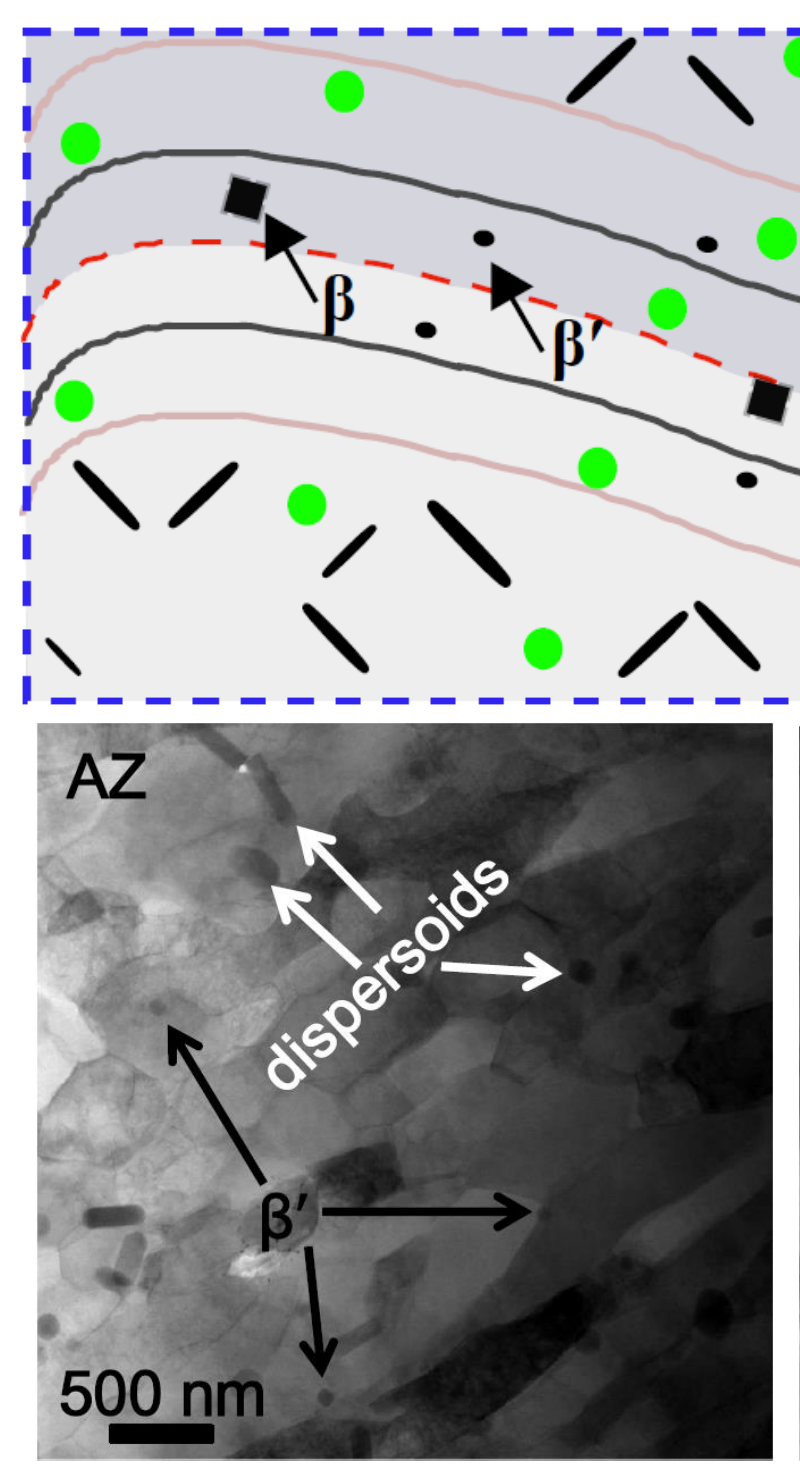

BM
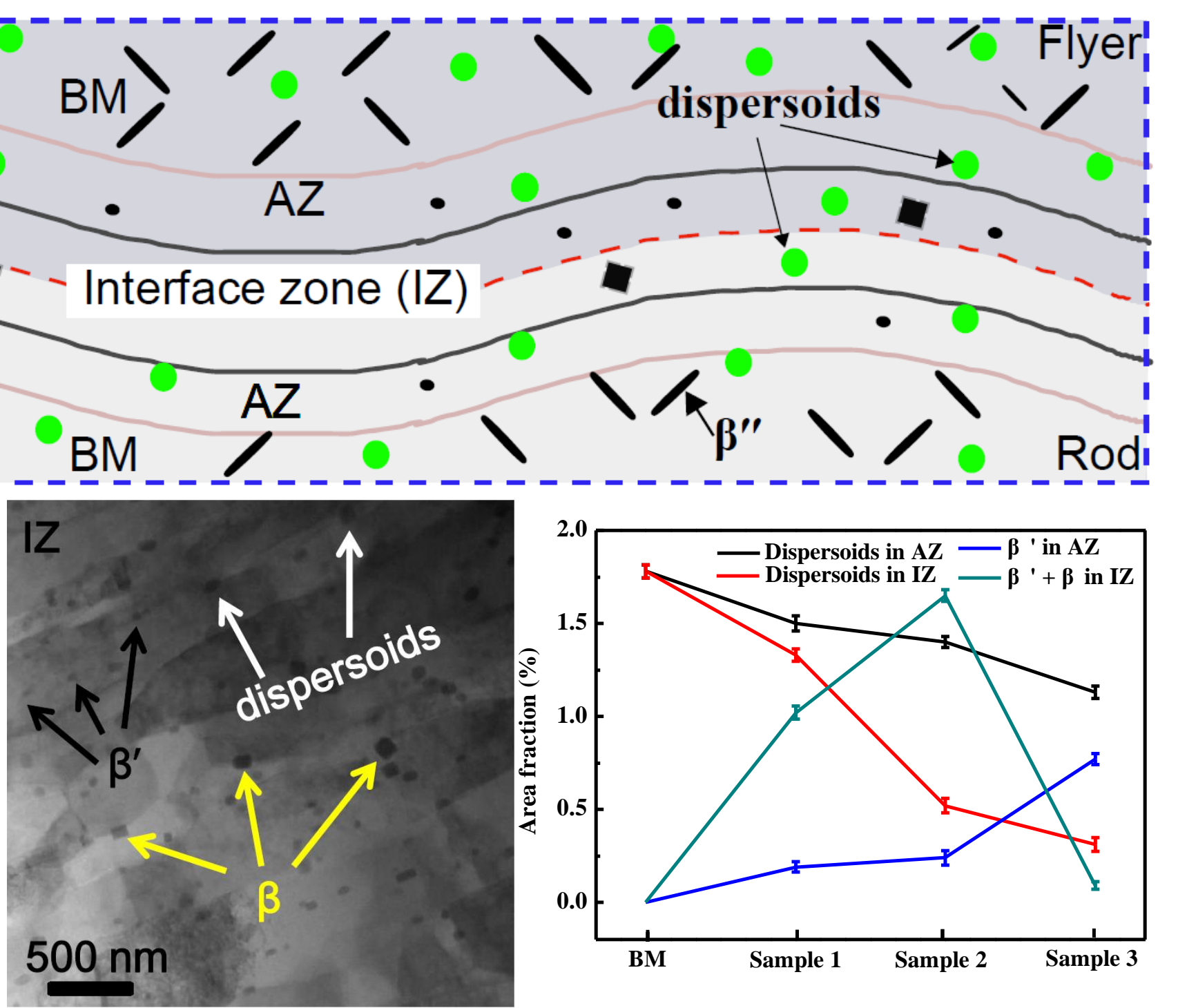